\title{
From intentions to births: paths of realisation in a multi-dimensional life course
}

\author{
Maria Rita Testa and Francesco Rampazzo*
}

\begin{abstract}
The adult lives of women and men are shaped by a wide range of choices and events pertaining to different life domains. In the literature, however, pregnancy intentions are typically studied in isolation from other life course intentions. We investigate the correspondence of birth intentions and outcomes in a life course cross-domain perspective that includes partnership, education, work, and housing. Using longitudinal data from the Generations and Gender Surveys, we examine the matching processes of individuals' birth intentions with subsequent outcomes in Austria, Bulgaria, France, Hungary, and Lithuania. The results show that the intention to change residence is directly correlated with having a child among men and women living in a union, and that the intention to enter a partnership is correlated with childbearing among single men, but not among single women. Furthermore, we find that the intention to change jobs is inversely correlated with an intended childbirth, while it is directly correlated with an unintended childbirth These findings suggest that the transition paths from birth intentions to birth outcomes should encompass a multi-dimensional life course perspective.
\end{abstract}

\section{Introduction}

The interplay of individual life paths is a key dimension for understanding why couples do not always achieve their previously stated childbearing goals. With a few exceptions (e.g., Barber 2001; Philipov 2009), the link between fertility intentions and outcomes has been assessed in the literature in isolation from intentions and analogous links in other life course domains. With the aim of filling this gap,

\footnotetext{
* Maria Rita Testa (corresponding author), Wittgenstein Centre (IIASA, VID/ÖAW, WU),

Vienna Institute of Demography/Austrian Academy of Sciences, Welthandelsplatz 2, 1020 Vienna, Austria

E-mail: maria.rita.testa@oeaw.ac.at

Francesco Rampazzo, University of Southampton, UK
}

DOI: 10.1553/populationyearbook2018s177 
we study in this paper the link between birth intentions and outcomes using a multidimensional perspective, and following adult individuals in several areas of life, including partnership, education, work, and housing. These domains are closely interrelated, and all of them influence the family formation process.

The incompatibilities or conflicts between the roles of parent, student, and worker have contributed considerably to the decline in and the postponement of fertility observed in all developed countries (Gauthier 2007). In many countries, the traditional sequence of family events has been replaced by a de-standardisation of the life course, which means that patterns of family formation are becoming increasingly heterogeneous, and do not follow a predefined sequence. In the destandardisation process, biographies become open and dependent upon decisionmaking, and are removed from the traditional precepts and certainties, as well as from external controls and general moral laws (Beck and Beck-Gernsheim 1995). This process goes hand-in-hand with the increased number of options that individuals are able to choose from, and that they expect to make decisions about. To study the increasingly complex sequencing of family life courses, approaches that encompass a multidimensional life course perspective are needed (Berrington et al. 2015).

We address this challenge and expand the existing literature on reproductive intentions by studying the intention-behaviour link within the framework of a number of different life intentions of adult individuals. Our research question is as follows: How does a multidimensional life course plan affect the translation of birth intentions into birth outcomes? Which of the life course intentions other than childbearing ease or hinder the realisation of birth intentions? We focus on a set of alternative intentions for which cross-national longitudinal data are available: education, partnership, work, and housing. These intentions are interrelated with the childbearing sphere of life, and thus influence the family formation process.

\section{Theoretical background}

From a life course perspective, a biography can be seen as a sequence of biographical transitions in different domains that are interdependent. Individuals decide on which activities they will perform in different life course domains on the basis of their goal-related aspirations and expectations. Raising children, being employed, getting an education, and owning a house are interrelated lifetime goals that positively contribute to a person's subjective well-being. In this range of options, fertility is a goal-seeking behaviour over the life course, while parenthood is either an ultimate or an intermediate goal that is expected to improve the individual's social well-being through the affection and the social approval that arises from the parentchild relationship (Huinink and Kohli 2014).

The life course approach is based on several principles, including those of situational imperatives, linked lives, agency, and life stage (Elder et al. 2003). The principle of agency refers to a subject constructing her/his life course and biography 
as a self-monitored actor within the particular opportunities and constraints s/he faces. For example, two or more persons who have the same socio-economic background may nonetheless follow different residential move and occupational career paths. Social scientists usually refer to the concept of agency as the intrinsic human capacity to make choices and act (Giddens 1984), or as the personal resources that are brought to bear when taking action. In this latter definition, agency can be measured empirically and operationalised by psychological concepts like self-efficacy (Bandura 1997). The concept of agency is crucial in life course research because the process of individualisation, accelerated social change, and the uncertainty of the modern 'risk society' (Beck 1992) have made status passages increasingly conditional, and thus impose agentic behaviour upon the individual People do not merely follow institutionally prescribed pathways; but actively participate in societal domains like education, the labour market, and family Thus, a subject constructs her/his life course as a self-monitored actor within historical socio-economic circumstances. Heinz (1996) has argued that individuals are biographical actors, and as such they do not simply follow social norms, or engage in subjective utility-maximising behaviour, but pursue their own goals and biographical plans while evaluating structural opportunities and institutional constraints.

To put the principle of agency to work in empirical research, the rational choice theory or any other theory of action may be applied. One theory that is commonly cited in the study of reproductive decision-making is the theory of planned behaviour (Billari et al. 2009; Ajzen and Klobas 2013; Dommermuth et al. 2011; Mencarini et al. 2014). According to this model, intentions are the result of three groups of factors: attitudes towards the behaviour; the perceived norms formed under the influence of social pressure; and the perceived behavioural control, or the extent to which individuals think they can exercise control over factors that have a major influence on their behaviour. This last group of factors is close to the concept of self-efficacy proposed by Bandura (1997). Within the framework of the TPB theory, some scholars have studied attitudes towards goals that compete with childbearing, such as educational attainment, professional career development, and consumer spending (Barber 2001; Barber et al. 2002; Barber and Axinn 2005). Using US longitudinal data, Barber (2001) provided evidence that attitudes towards alternative behaviours are background factors that influence the three blocks of determinants of childbearing intentions in the TPB. Similarly, Philipov (2009) showed that in Bulgaria, the intention to pursue higher education competes with childbearing; whereas the intention to enter employment, or the status of actually being employed, facilitates the realisation of childbearing intentions. The studies by Barber (2001) and Philipov (2009) both predicted that competing life domains would influence the paths through which childbearing intentions are translated into actual behaviour. The first study (Barber 2001) assumed, however, that the mechanism of influence works mainly through the formation of new attitudes affecting childbearing intentions, while the second study (Philipov 2009) posited that competing intentions have a direct influence on both birth intentions and the 


\section{Scheme 1:}

Intentions in several life course domains and their influence on childbearing

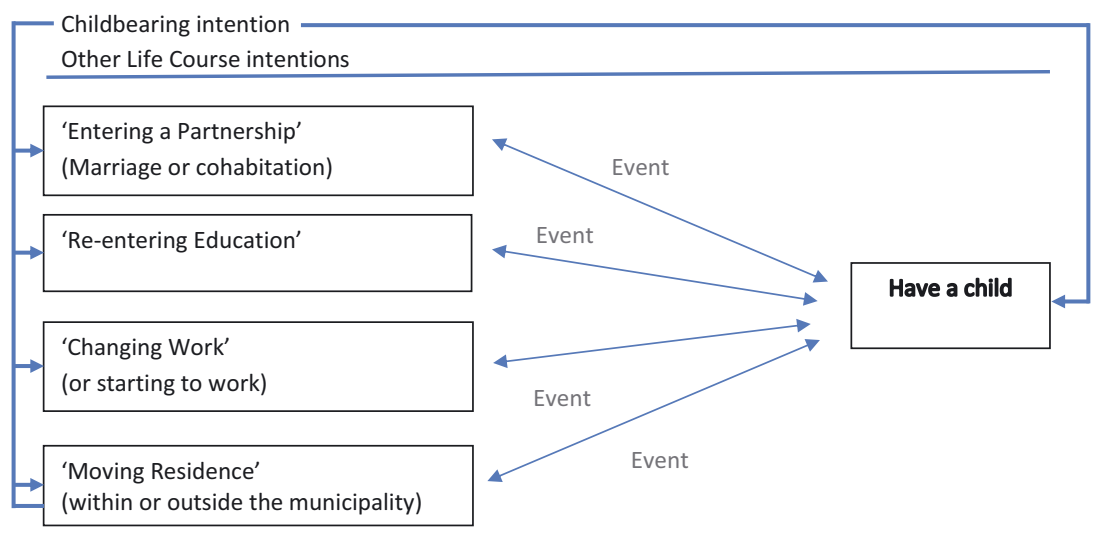

Note: The effects of life course intentions on the likelihood of having a child is twofold: one is merely due to the cross-domain intentions and the other is due to the corresponding cross-domain events. Because of a lack of accurate data, we restrict the analysis to the effects exerted by life course intentions.

realisation of birth intentions. In this paper, we concentrate on the cross-domain influence of other life course intentions on births. We do not deny that life course intentions may have an effect on birth intentions as well. But given the constraints on the available data, we prefer to restrict the empirical analysis to the effects of life course intentions on childbirth.

When two events in different life domains compete with each other and cannot be realised at the same time, the individual may decide to either give up definitively on one of them, or establish a temporal order of the events over the life course. The conflict between the events can sometimes resolve itself spontaneously over the course of life. For example, being enrolled in education may conflict with the formation and the realisation of a woman's pregnancy intentions at early reproductive ages; but later on, after the woman has already made the transition to parenthood, her intention to return to education can be complementary with her birth intentions and birth outcomes. In the life course theory, the different domains of life and the decision-making processes that govern transitions to different life states are assumed to be interrelated. Education, partnership, childbearing, work, and housing are examples of different 'careers' that are simultaneously present in a person's life. Each of these careers consists of a number of transitions, or changes of state, and the durations (length of time) between these transitions will vary (Elder 1985; Elder et al. 2003). Events in one career can hinder, enable, delay, or anticipate events in others; a phenomenon known as 'interdependencies of parallel careers' (Dykstra and van Wissen 1999). The organisation of one's own life course implies the existence of a complex decision-making process (Blossfeld et al. 2005) in which 
intentions are a main component. In this paper, we study such decisions before they are implemented in the form of a behavioural outcome by looking at the relationship between birth and other life course intentions on the one hand, and birth intentions and birth outcomes on the other (Scheme 1).

\section{Research hypotheses}

Over the life course, individuals often have a large number of competing life goals (Blossfeld et al. 2005). The wide range of available choices make the decisionmaking process complex and the paths to realisation highly heterogeneous. The multiple roles individuals occupy simultaneously can make it challenging for them to fulfil their reproductive intentions. Understanding the impact of these intentions on childbearing requires the formulation of specific research hypotheses for each life course domain.

Being in a partnership is a precondition for having children (Schoen et al. 1999), regardless of whether the partnership is formalised through marriage. Hence, we expect to find that the intention to enter a union is positively correlated with the birth of a child among single men and women (Hypothesis 1a). Moreover, since being married indicates that the partners have a higher level of reciprocal commitment (Hiekel and Castro-Martin 2014), we anticipate that the intention to marry is positively correlated with the birth of a child among cohabiting men and women (Hypothesis 1b).

There is ample literature on the conflict between enrolment in education and childbearing. Previous studies have found that the tasks associated with these life domains cannot be easily reconciled (Blossfeld and Huinink 1991; Billari and Philipov 2004). We extend these findings to the case of the return to education. ${ }^{1}$ We therefore expect to find that the intention to return to education reduces the likelihood of having a child for both singles and couples (Hypothesis 2).

Work competes with childbearing because of opportunity costs, which are normally higher for women than for men, as in most couples and societies mothers perform most of the household and childcare duties (Thomson and Brandreth 1995). Similarly, a job change might be associated with individual aspirations for career advancement, which could negatively influence childbearing (Philipov 2009). Based on the dominant age norm, young adults (ages 18-39) in particular may be expected to prioritise pursuing a working career over childbearing. Hence, we anticipate that the intention to start working or to change jobs is inversely correlated with childbearing for both singles and couples (Hypothesis 3).

\footnotetext{
1 Only a very tiny percentage of our available sample (3\%) consisted of individuals who were still in education and exposed to (the intention to) complete their studies. For this reason, we focused on the intention to return to education.
} 
A move to another municipality, or to another dwelling within the same municipality, is often associated with an attempt to improve one's socio-economic status. Individuals frequently move because they want to live in a bigger flat or house, which is in turn likely to create suitable conditions for childbearing. Alternatively, individuals may move because they plan to expand their family; i.e., the move may be an anticipatory relocation to adapt to a growing household size (Vidal et al. 2017). Hence, we expect to find that the intention to change residence is positively associated with childbearing for both singles and individuals living in a union (Hypothesis 4).

\section{Data, measures, and models}

We used two follow-up waves of the Generations and Gender Surveys (GGS) for five European countries, including Austria, Bulgaria, France, Hungary, and Lithuania. As the Generations and Gender surveys are part of an international programme that uses an international questionnaire, GGS data are suitable for cross-national comparative analyses (Vikat et al. 2007). It should be noted, however, that the extent to which the country questionnaires have been harmonised, and the overall quality of each national survey dataset, can vary (Fokkema et al. 2016).

The national surveys were conducted in different years within the 2003-2013 period. The intervals between survey waves were three years in France, Lithuania, and Bulgaria and four years in Austria and Hungary. ${ }^{2}$ We selected only men and women of reproductive ages (ages 18-49) who provided valid answers to the questions on short-term fertility intentions at the first round of the survey, which resulted in a sample of 14,439 respondents, including 3,129 single men and women and 11,310 individuals living in a union. In the paper, the analysis refers to the pooled country dataset. Within this sample, Bulgaria and Hungary have the largest sample sizes, while Austria and France have medium sample sizes, and Lithuania has the smallest sample size (Table 1).

The birth of a child is the outcome variable. Respondents who were reinterviewed at the second wave were asked whether they had a child during the period between the surveys ('Did you have a child in the last three years?'). The consistency of this variable has been cross-checked with information coming from the household grid questionnaire items from which we recovered the date of birth of each family member. Female respondents who were already pregnant at the time of the first survey (748 in the pooled country dataset) were excluded from the analysis because it was not clear whether their answers referred to the child they were currently expecting or to the next child; thus, the intended births included in

2 Sensitivity analysis showed that the different time spans between the two survey waves in the different countries did not have a statistically significant effect on the likelihood of having a child. 
the analysis are expected to occur at least nine months after the date of the first survey.

The intention to have a child, as measured at the time of the first survey, is the key explanatory variable. The survey question reads: "Do you intend to have a child in the next three years?" The item has four response options: definitely yes, probably yes, probably not, and definitely not. The same options were included in the questions regarding the other intentions. The question about the intention to return to education is phrased as follows: "Do you intend to return to education in the next three years?" The intention items pertaining to the partnership domain are: "Do you intend to start living with a partner in the next three years?" or "Do you intend to marry in the next three years?" The intention items pertaining to the work domain are: "Do you intend to change companies or start a business in the next three years?" or "Do you intend to take a job or start a business in the next three years?' Finally, the intention to change residence is measured with the following question: "Do you intend to move in the next three years?" In this item, a move refers to a general change of residence, regardless of whether it is in the same municipality.

For the sake of simplicity, birth intentions were computed on a binary scale that groups together the probably and definitely yes answers and the probably and definitely not answers. This approach was necessary because some countries, like Hungary, coded childbearing intentions on a binary scale, rather than on a fourcategory scale. Individuals with missing information for births or any of the other life course intentions variables were excluded from the analysis. Missing records accounted for $12 \%$ of the country pooled dataset, and were almost evenly distributed across countries. ${ }^{3}$

Life course intentions other than those related to education were coded as dichotomous variables. The intention to return to education was computed by contrasting those individuals who intended to experience the event with a category that groups together those individuals who had not been asked because they had not been exposed to the event (e.g., those who were enrolled in education could not return to education) with those individuals who reported a negative answer. This latter group was retained as a separate dummy in the models only if the related effect was statistically significantly. To measure the intention to change jobs, we merged together the binary variable indicating a job change (for those individuals who were already employed) and the binary variable indicating the transition from unemployed/inactive to employed (for those individuals who were not employed). This approach enabled us to deal with the problem that some individuals were not exposed to the risk of experiencing the event of interest. The intention to change residence can be experienced by all individuals regardless of their characteristics; thus, a simple dichotomous variable indicating the change has been computed for this life domain.

3 Sensitivity analysis did not show a noticeable selection effect based on this reduction of the initial target sample. 
The control variables include age, gender, educational attainment (partner's educational attainment), marital status, and employment status (partner's employment status). All of the variables were considered as measured at the time of the first survey. The country dummies estimated the cross-national variance in the probability of having a birth. Summary statistics for model covariates (also broken by parity) can be reviewed in Table 1 .

Woman's age, the only numeric variable, was centred on the rounded mean values of 29 and 31 among single men and women, and of 37 and 35 among men and women living in a union. The level of education was a three-category variable, with low, medium, and high levels corresponding to levels 0-2, 3-4, and 5-6 of the International Standard Qualification of Education. The intention to marry was included in the models run on couples; while the intention to enter a relationship, either marriage or cohabitation, was included in the models run on singles. Employment status had the following four categories: employed, unemployed, not active, enrolled in education, and retired or other. The sub-sample of singles was evenly distributed across men and women. The men and women in this sub-sample were similarly likely to have a high level of education level $(62 \%$ of men and 57\% of women) and to be employed (about 58\% of men and women). However, $33 \%$ of single women, but just $11 \%$ of single men, already had a child. Around three out of four individuals living in a union were married (78\%), two out of three were highly educated, and more than half had a partner with a medium level of education (55\% of men and $64 \%$ of women). Finally, majorities of both men and women in a couple were employed (86\% of men and $67 \%$ of women) and had a partner who was employed (64\% of men and $86 \%$ of women) (Table 1).

Logistic regression models were performed separately on singles and individuals living in a union because the two categories referred to different stages of each individual's life course, and thus required different sets of predictor variables. Because we did not want to reduce the already stratified sample sizes, we pooled together individuals at different parity statuses, even though the marked differences between the transition to parenthood and the transition to a higher-order birth would have required us to perform a separate analysis. This methodological choice enabled us avoid ending up with a fragmented analysis based on very small sample sizes, which would have generated weak empirical results.

\section{Results}

\subsection{Birth and other life course intentions}

Around $70 \%$ of men and women expressing an intention to have a child had other life course intentions as well: $34 \%$ had one other intention, $27 \%$ had two other intentions, and $15 \%$ had three or more other intentions. It is thus clear that for the adults in the sample, decision-making was often multidimensional. Figure 1 
Table 1:

Distribution of the control variables used in the regression analysis. Per cent values

\begin{tabular}{|c|c|c|c|c|c|}
\hline \multirow{2}{*}{ Control variables } & & \multicolumn{2}{|c|}{ Singles } & \multicolumn{2}{|c|}{ Couples } \\
\hline & & Male & Female & Male & Female \\
\hline Age & Age (mean) & 29.09 & 30.71 & 37.00 & 35.24 \\
\hline \multirow[t]{2}{*}{ Gender } & Female & 49.86 & 50.14 & 41.78 & 58.22 \\
\hline & Male & 50.14 & 49.86 & 58.22 & 41.78 \\
\hline \multirow[t]{2}{*}{ Parity } & No child & 98.78 & 77.56 & 14.15 & 12.92 \\
\hline & $\begin{array}{l}\text { One or more } \\
\text { children }\end{array}$ & 11.22 & 32.44 & 85.85 & 87.08 \\
\hline \multirow[t]{2}{*}{ Relationship status } & Cohabiting & & & 21.91 & 21.12 \\
\hline & Married & & & 78.09 & 78.88 \\
\hline \multirow[t]{3}{*}{ Educational attainment } & Low level & 22.63 & 32.12 & 18.09 & 18.73 \\
\hline & Medium level & 15.64 & 10.96 & 11.13 & 11.16 \\
\hline & High level & 61.73 & 56.92 & 69.97 & 69.25 \\
\hline \multirow[t]{3}{*}{ Partner's educ. attainment } & Low level & & & 5.63 & 4.57 \\
\hline & Medium level & & & 55.39 & 63.47 \\
\hline & High level & & & 38.98 & 31.97 \\
\hline \multirow[t]{5}{*}{ Employment status } & Employed & 58.01 & 58.64 & 85.75 & 66.67 \\
\hline & Unemployed & 20.06 & 13.19 & 9.87 & 10.66 \\
\hline & Housework & 0.06 & 2.68 & 0.45 & 18.94 \\
\hline & Student & 16.28 & 22.43 & 0.5 & 1.35 \\
\hline & Other & 5.58 & 3.06 & 3.42 & 2.38 \\
\hline \multirow{5}{*}{$\begin{array}{l}\text { Partner's employment } \\
\text { status }\end{array}$} & Employed & & & 64.36 & 86.11 \\
\hline & Unemployed & & & 10.52 & 9.11 \\
\hline & Housework & & & 21.07 & 0.22 \\
\hline & Student & & & 1.56 & 0.57 \\
\hline & Other & & & 2.49 & 3.93 \\
\hline \multirow[t]{5}{*}{ Countries } & Austria & 24.10 & 25.81 & 16.67 & 18.91 \\
\hline & Bulgaria & 55.38 & 44.3 & 27.85 & 32.15 \\
\hline & France & 20.51 & 29.89 & 17.15 & 17.37 \\
\hline & Hungary & & & 31.88 & 26.79 \\
\hline & Lithuania & & & 6.45 & 4.77 \\
\hline Sample size & & 1560 & 1569 & 4618 & 6435 \\
\hline
\end{tabular}

Note: In Hungary and Lithuania, singles were not interviewed.

displays the univariate distribution of each of these life course intentions by gender, and separately for singles and couples. The intention to have a child was reported by $31 \%$ of single men and $22 \%$ of single women (Figure 1, panel a). This was not 
Figure 1:

Birth intentions and other life course intentions by gender. Pooled country dataset

Panel a) Single women and men

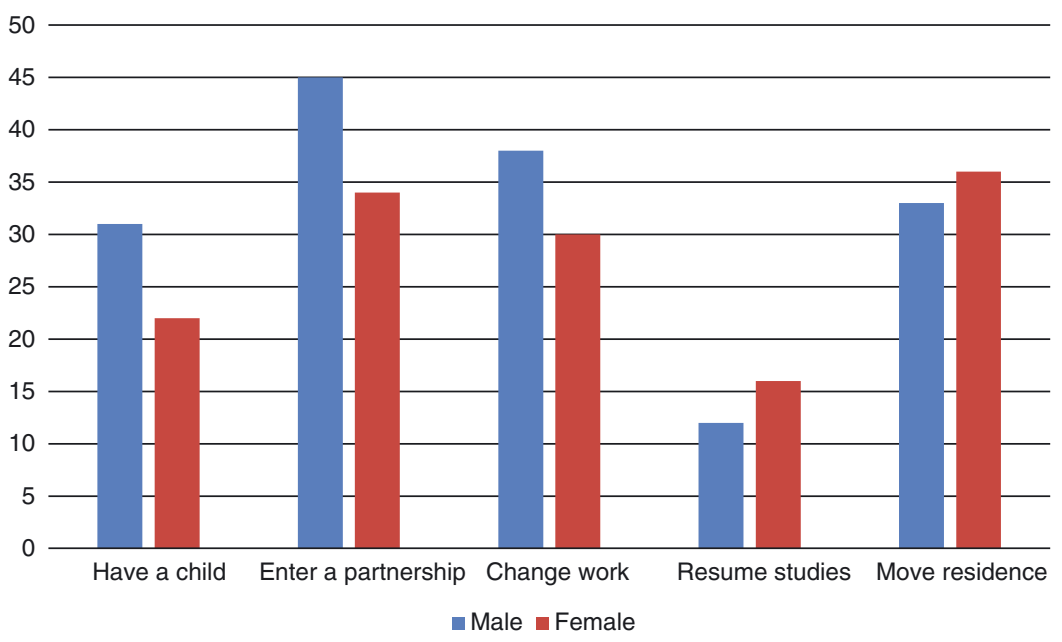

Panel b) Women and men living in a union

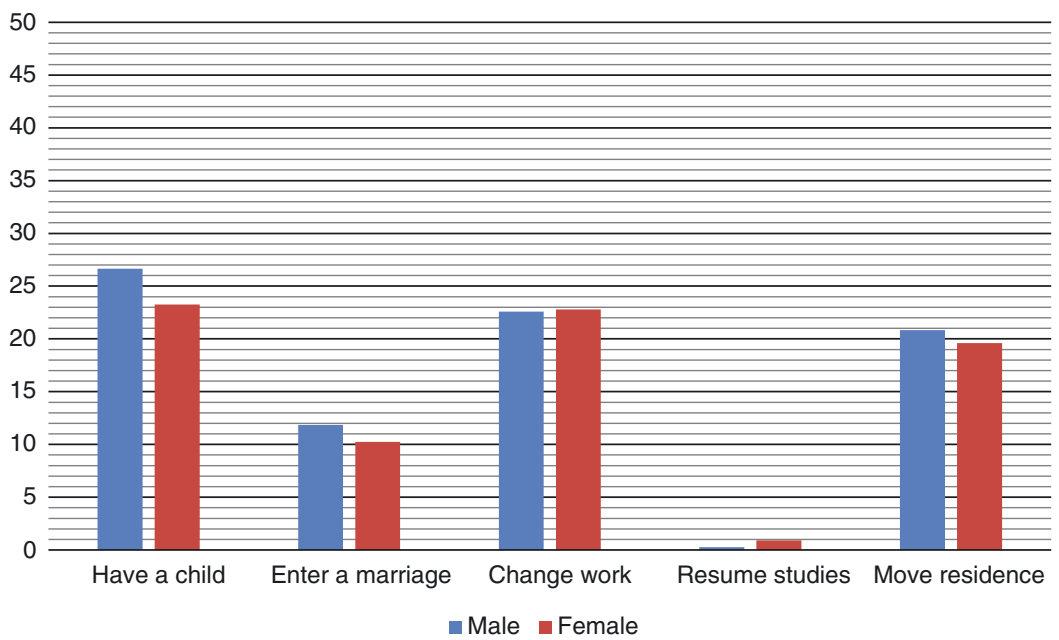

the most frequently expressed intention, as individuals were more likely to report having intentions in the education, work, and housing domains: $45 \%$ of men and $34 \%$ of women said they intend to enter a partnership, $37 \%$ of men and $30 \%$ of women said they intend to change jobs, and $33 \%$ of men and $36 \%$ of women said they intend to move house. Finally, $12 \%$ of men and $16 \%$ of women said they intend to return to education. Intentions to make changes in the work and partnership 
domains were more common among men, while intentions to make changes in the housing and educational domains were more common among women. Birth intentions were more common among men than among women (Figure 1, panel a).

Individuals living in a couple were most likely to express an intention to make a transition to a different status in the domains of childbearing, work, and housing. The gender differences were very small in this sub-group: $26 \%$ of men and $24 \%$ of women said they intend to have a child, $23 \%$ of men and $24 \%$ of women said they intend to change job, $21 \%$ of men and $19 \%$ of women said they intend to move house, and $12 \%$ of men and $10 \%$ of women said they intend to marry. The intention to return to education was expressed by less than $1 \%$ of the individuals living in a union (Figure 1, panel b).

In order to estimate the effects of all of the intentions studied - including of birth and other life course intentions - on the probability of having a child, we ran a logistic regression analysis that included the various life course intention variables, as well as a set of variables that controlled for the socio-demographic characteristics of adult individuals. We present the outcomes of the analysis in the next section.

\subsection{Realisation of birth intentions}

In the models for single men and women, none of the other life course intention variables was significant, with the exception of 'enter a partnership', which was positively associated with a childbirth. Age was negatively correlated with childbearing, but having already had at least one child was positively correlated with further childbearing. Highly educated men were less likely than medium educated men to have a child. Single men and women living in Austria were more likely to have a child than their counterparts living in Bulgaria (Table 2, panel a). Lithuania and Hungary could not be included in this analysis because questions about these intentions were posed only to respondents living in a union.

The outcomes of the models for individuals living in a union suggest that the intention to change residence increased the likelihood of having a child (Table 2, panel b). This result was robust across all three models. None of the other life course intention variables had a significant influence on the likelihood of having a child. Childbirth was negatively correlated with age and parity: the older an individual was, the less likely s/he was to have a child; and the more children the individual had, the less likely s/he was to have another child. Women were less likely than men to have a child. Furthermore, the birth of a child was negatively associated with a high educational level among men, but not among women. The partner's educational level displayed a U-shaped pattern, whereby the probability of having a child was highest for individuals with a partner in the low or in the high educational level category. Being a housewife increased the chances of having a child among women. Being unemployed increased the likelihood of having a child among men only. Men and women in Austria and in Hungary were more likely to have a child than their counterparts in Bulgaria. The results were similar for France, 
Table 2:

Panel a) Logistic regression on having a child for singles. Beta coefficients

\begin{tabular}{|c|c|c|c|c|}
\hline Variables & Labels & All & Male & Female \\
\hline \multicolumn{5}{|l|}{ Intentions variables } \\
\hline Childbearing & Have a child, yes & $\begin{array}{l}0.917^{* * *} \\
(0.202)\end{array}$ & $\begin{array}{l}0.707^{* *} \\
(0.284)\end{array}$ & $\begin{array}{l}1.035^{* * *} \\
(0.291)\end{array}$ \\
\hline Partnership & Enter a partnership, yes & $\begin{array}{c}0.278 \\
(0.198)\end{array}$ & $\begin{array}{l}0.647^{* *} \\
(0.291)\end{array}$ & $\begin{array}{c}-0.0772 \\
(0.281)\end{array}$ \\
\hline Education & Return to education, yes & $\begin{array}{l}-0.225 \\
(0.604)\end{array}$ & $\begin{array}{l}-1.324 \\
(-1.010)\end{array}$ & $\begin{array}{c}0.379 \\
(0.808)\end{array}$ \\
\hline Work & Change jobs, yes & $\begin{array}{l}-0.112 \\
(0.223)\end{array}$ & $\begin{array}{l}-0.413 \\
(0.323)\end{array}$ & $\begin{array}{c}0.123 \\
(0.321)\end{array}$ \\
\hline Residence & Move house, yes & $\begin{array}{c}0.278 \\
(0.179)\end{array}$ & $\begin{array}{c}0.249 \\
(0.257)\end{array}$ & $\begin{array}{c}0.323 \\
(0.255)\end{array}$ \\
\hline \multicolumn{5}{|l|}{ Control variables } \\
\hline \multirow[t]{2}{*}{ Age } & Age & $\begin{array}{c}-0.063^{* * *} \\
(0.0166)\end{array}$ & $\begin{array}{l}-0.038^{*} \\
(0.0228)\end{array}$ & $\begin{array}{c}-0.090^{* * *} \\
(0.0254)\end{array}$ \\
\hline & Age squared & $\begin{array}{c}-0.008^{* * *} \\
(0.002)\end{array}$ & $\begin{array}{c}-0.007^{* *} \\
(0.003)\end{array}$ & $\begin{array}{c}-0.009^{* * *} \\
(0.003)\end{array}$ \\
\hline $\begin{array}{l}\text { Gender } \\
\text { (ref. Male) }\end{array}$ & Female & $\begin{array}{l}0.0834 \\
(0.181)\end{array}$ & & \\
\hline $\begin{array}{l}\text { Parity } \\
\text { (ref. No child) }\end{array}$ & At least one child & $\begin{array}{c}0.763^{* * *} \\
(0.264)\end{array}$ & $\begin{array}{l}1.006^{* * *} \\
(0.388)\end{array}$ & $\begin{array}{l}0.683^{*} \\
(0.358)\end{array}$ \\
\hline \multirow[t]{2}{*}{$\begin{array}{l}\text { Education } \\
\text { (ref. Medium level) }\end{array}$} & Low level & $\begin{array}{l}0.0952 \\
(0.469)\end{array}$ & $\begin{array}{c}0.471 \\
(0.638)\end{array}$ & $\begin{array}{c}-0.0474 \\
(0.716)\end{array}$ \\
\hline & High level & $\begin{array}{c}-0.584^{* *} \\
(0.243)\end{array}$ & $\begin{array}{l}-0.607^{*} \\
(0.329)\end{array}$ & $\begin{array}{l}-0.562 \\
(0.365)\end{array}$ \\
\hline \multirow[t]{2}{*}{$\begin{array}{l}\text { Employment } \\
\text { (ref. Employed) }\end{array}$} & Unemployed & $\begin{array}{c}0.008 \\
(0.268)\end{array}$ & $\begin{array}{l}-0.134 \\
(0.389)\end{array}$ & $\begin{array}{c}0.203 \\
(0.379)\end{array}$ \\
\hline & Housework & $\begin{array}{c}0.416 \\
(0.569)\end{array}$ & & $\begin{array}{c}0.584 \\
(0.717)\end{array}$ \\
\hline \multirow[t]{2}{*}{$\begin{array}{l}\text { Country } \\
\text { (ref. Bulgaria) }\end{array}$} & France & $\begin{array}{l}-0.584 \\
(0.479)\end{array}$ & $\begin{array}{c}-1.210^{*} \\
(0.692)\end{array}$ & $\begin{array}{l}-0.219 \\
(0.698)\end{array}$ \\
\hline & Austria & $\begin{array}{c}0.636^{* * *} \\
(0.206)\end{array}$ & $\begin{array}{c}0.323 \\
(0.296)\end{array}$ & $\begin{array}{l}0.929^{* * *} \\
(0.299)\end{array}$ \\
\hline Constant & & $\begin{array}{c}-4.065^{* * *} \\
(0.760)\end{array}$ & $\begin{array}{c}-3.386^{* * *} \\
(0.970)\end{array}$ & $\begin{array}{c}-4.380^{* * * *} \\
(1.052)\end{array}$ \\
\hline Sample size & & 3,129 & 1,560 & 1,569 \\
\hline
\end{tabular}

Note: Standard errors in parentheses. ${ }^{* * *} p<0.01,{ }^{* *} p<0.05,{ }^{*} p<0.1$. 
Table 2:

Panel b) Logistic regression on having a child for couples. Beta coefficients

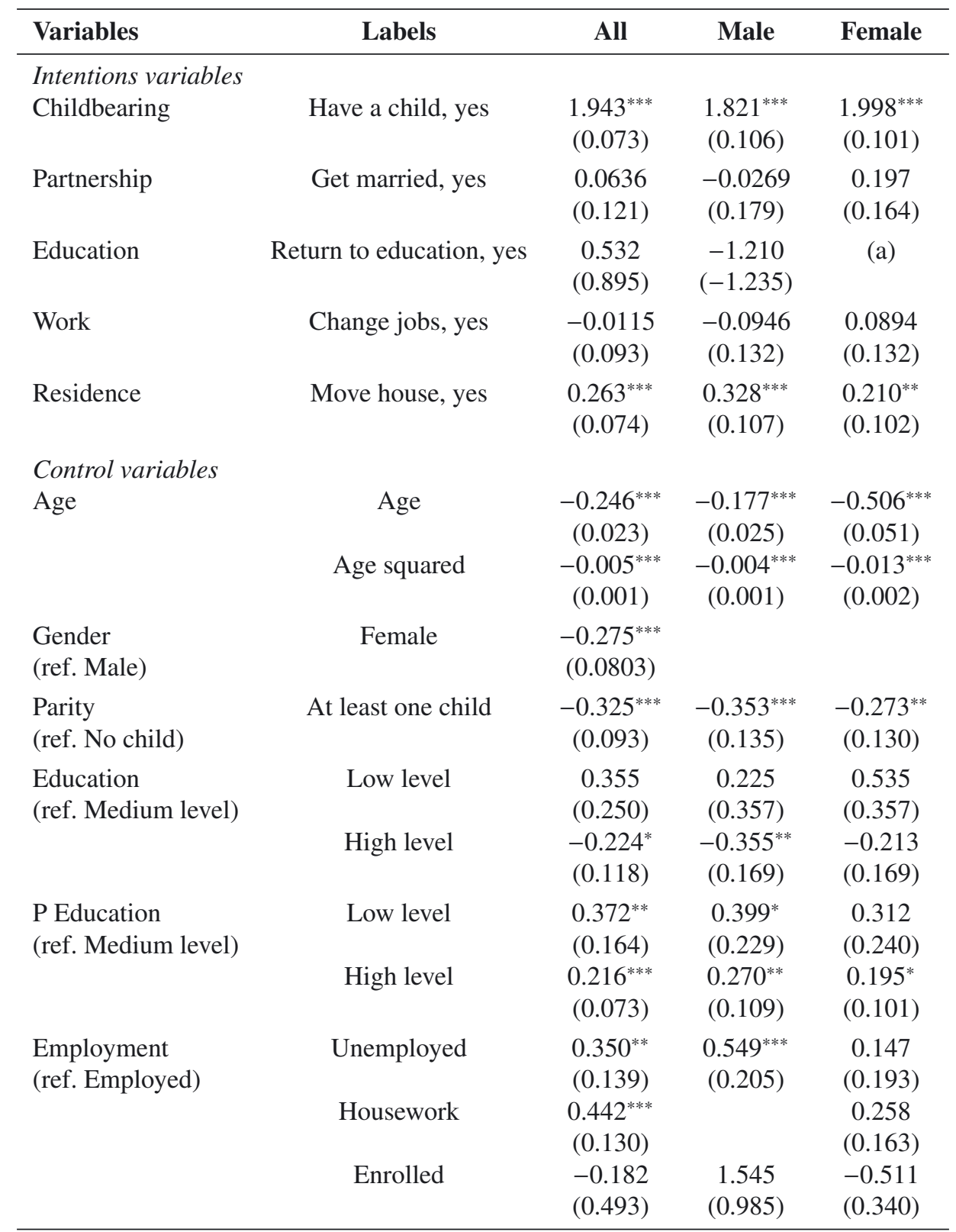

Continued 
Table 2:

Panel b) Continued

\begin{tabular}{lcccc}
\hline Variables & Labels & All & Male & Female \\
\hline P. employment & & & & \\
(ref. Employed) & Unemployed & -0.090 & -0.194 & -0.019 \\
& & $(0.135)$ & $(0.202)$ & $(0.185)$ \\
& Housework & $0.521^{* * *}$ & $0.555^{* * *}$ & \\
& & $(0.116)$ & $(0.124)$ & \\
& Enrolled & -0.162 & 0.0295 & -0.403 \\
& & $(0.252)$ & $(0.307)$ & $(0.448)$ \\
Country & France & $0.424^{*}$ & 0.366 & 0.371 \\
(ref. Bulgaria) & & $(0.253)$ & $(0.365)$ & $(0.357)$ \\
& Hungary & $0.982^{* * *}$ & $0.946^{* * *}$ & $0.991^{* * *}$ \\
& & $(0.105)$ & $(0.155)$ & $(0.144)$ \\
& Austria & $1.220^{* * *}$ & $1.226^{* * *}$ & $1.254^{* * *}$ \\
& & $(0.112)$ & $(0.170)$ & $(0.153)$ \\
& Lithuania & 0.221 & 0.197 & 0.250 \\
& & $(0.179)$ & $(0.256)$ & $(0.251)$ \\
Constant & & $-5.772^{* * *}$ & $-5.687^{* * *}$ & $-7.818^{* * *}$ \\
& & $(1.000)$ & $(1.429)$ & $(0.450)$ \\
Sample size & & 11,310 & 4,900 & 6,410 \\
\hline
\end{tabular}

Note: Standard errors in parentheses. ${ }^{* * *} p<0.01, * * p<0.05,{ }^{*} p<0.1$

(a) The variables were dropped from the regression because the cell size was too small.

but in this case, statistical significance was reached in the pooled gender models only (Table 2, panel b). Interestingly, among cohabiting couples, the intention to get married did not significantly influence the likelihood of having a child (Table 2, panel b). Childbearing was conditioned on being in a union, irrespective of whether the union took the form of cohabitation or marriage.

Our observation period was relatively short (i.e., three years). As the life course intentions (i.e., intentions related to partnership, education, work, and housing) of individuals who intend to have (more) children might be strongly interrelated, endogeneity issues arise. To minimise the risk of endogeneity, we conducted a supplementary analysis of cross-domain intentions; the results of which are displayed in the appendix (Table A.1 panel (a) and panel (b)). In this analytical setting, the chances of birth occurrences were modelled conditionally to the sign of birth intentions, or to whether they are positive or negative. This methodological approach was chosen based on the distinctive and primary role of the intention to have a child in the transition path to a birth outcome. Indeed, women and men who do not intend to have children, but have other life course intentions, have already prioritised other life goals over childbearing, and will necessarily have a lower risk 
of having a child. The results of this analysis show that among singles who said they intend to have a child, only age, parity, and education significantly influenced their chances of having a child, with age having a negative effect and education and parity having positive effects. If an individual did not intend to have a child, having the intention to move house and living in Austria also positively influenced the likelihood of having a child. Among individuals who were living in a union, the intention to change jobs negatively affected their chances of having a child if they had planned to have a child, and it positively affected their chances of having a child if they had not planned to have a child. Furthermore, the intention to move house was statistically significant and positively correlated with childbearing. Among the control variables, parity status lost its significance if the birth was not planned, which means that whether an individual had a child did not depend on whether there were already children in the family.

\section{Concluding remarks}

Most of the studies on the correspondence between birth intentions and birth outcomes have considered this link in isolation from intention-behavioural links pertaining to other life course domains. In this paper, we examined for the first time the matching process between birth intentions and birth outcomes in a crossdomain context including partnership, education, work, and housing. All four of these domains contribute to the family formation process. Key to our analysis was the study of the intersection of the different life course domains through the link between life course intentions in education, partnership, work, and housing on the one hand; and childbearing on the other. The argument for using this approach is that the interdependence across life domains affects not only the observed events, but the preceding corresponding intentions. For each selected life course domain, we tested whether the corresponding life course intention facilitated or competed with the realisation of the birth intention using a longitudinal dataset derived from the Generations and Gender Surveys (GGS). The study included data from Austria, Bulgaria, France, Hungary, and Lithuania. Consistent with previous literature (Steele and Ermisch 2016), we found that intending to change residence was closely correlated with the realisation of childbirth. Hypothesis four is, however, only partially supported, because the result applied only to men and women living in a union. This finding might indicate that moving house plays a role only if the family is already consolidated in a stable relationship, and that the quantity or the quality of the living space only matters if the size of the family is expanding through the birth of a child. This empirical finding is in line with those of previous studies, according to which individuals with children are more likely than childless individuals to relocate (Vidal et al. 2017). In addition, the GGS data provided evidence that the intention to enter a partnership was correlated with the intention to have a child. However, this result held for single men, but not for single women. Hence, hypothesis one is only partially supported by the data. A possible explanation for 
this gender difference is that compared to men, women might want to wait longer to have a child after starting a union, or they might simply plan the events of entering a partnership and having a child more independently of each other. On the other hand, the results did not show that the intention to get married had any significant effect on childbearing, which implies that the precondition for childbearing was living in a union, regardless of whether the union was formalised through marriage. This result is consistent with only some of the existing literature. While it has been shown that marriage is a relevant predictor of the realisation of birth intentions (Schoen et al. 1999), a study conducted in France found no differences between cohabiting and married unions in the realisation of birth intentions (Testa and Toulemon 2006). Cross-national variations could be related to cross-country differences in the meaning of cohabitation (Hiekel and Castro-Martín 2014), but we were not able to test this claim in this paper because of the small national sample sizes. ${ }^{4}$

Finally, we could not find empirical evidence in support of hypothesis two regarding the intention to return to education, or for hypothesis three regarding the intention to change job. Both variables were found to be negatively correlated with childbearing among men and positively correlated with childbearing among women. We could speculate that changes in these life domains complement the realisation of birth intentions for women, but compete with the realisation of birth intentions for men. As this result was not statistically significant, further investigation in this direction should be pursued once more longitudinal data become available. Interestingly, our findings indicate that the effect of the intention to change jobs on having a child was conditioned on whether the birth intention was positive or negative. If the birth intention was positive, changing jobs conflicted with childbearing; whereas if the birth intention was negative, changing jobs was complementary with childbearing (see the results of the supplementary analysis reported in the appendix).

The analysis conducted in this paper contains some suggestions for further research in the field. In particular, we hope that our approach will eventually be expanded to additional countries and over time. In this paper, each country's specific institutional, economic, and normative characteristics have merely been treated as control variables. However, taking these dimensions into account is important for understanding the heterogeneity in cross-domains intentions. For example, the degree of competition between work and family choices depends on the options people have to combine these spheres of life in different institutional settings (Gauthier et al. 2016). Hence, observing a larger set of countries that also includes some Southern and Northern European countries could help to clarify the effects of institutional factors on childbearing. In addition, studying a larger number of groups (i.e., countries) could allow for the combination of micro- and macro-level analysis in a unitary (multi-level) framework. Using a longer period of observation could

4 Our finding that the interaction terms 'intention to marry * country' were not statistically significant might be due to the small national sample sizes. 
help to shed light on the conditional structure of multiple life course intentions, and to determine the differences in the chances of realisation depending on the temporal priority of each life goal in a single individual's life. Moreover, using a longer period would make it possible to study the cross-domain effect of the events, rather than just those of the intentions. Over a longer time period, a larger number of links between life course intentions and outcomes would emerge, and these links could be ordered temporally in relation to births and other life course domains.

Our contribution to the literature is twofold. First, we extended previous studies on childbearing intentions to a broader set of alternative life course intentions, and emphasised that some intentions do not compete with, but rather facilitate the realisation of childbearing intentions (e.g., moving house). Second, by studying the influence of cross-domain intentions on the realisation of childbearing intentions, we provided an original interpretation of the mismatch between birth intentions and birth outcomes, and urged the inclusion of several life course intentions in studies on the predictive power of birth intentions. Despite the limits of this research, we have shown that various life course intentions - and especially the intention to enter a partnership and the intention to move house - matter, and need to be considered in the analysis of childbearing and the family life course.

\section{References}

Ajzen, I. 1991. The theory of planned behavior. Organizational Behavior and Human Decision Processes 50: 179-211.

Ajzen, I. and J. Klobas 2013. Fertility intentions: an approach based on the theory of planned behavior. Demographic Research 29(8): 203-232.

Barber, J. 2001. Ideational influences on the transition to parenthood: attitudes toward childbearing and competing alternatives. Social Psychology Quarterly 64(2): 101-127.

Barber, J., W. Axinn and A. Thornton 2002. The influence of attitudes on family formation processes. In: Meaning and Choice: Value Orientations and Life Course Decisions, ed. R. Lesthaeghe, NIDI CBGS Publications.

Barber, J. and W. Axinn 2005. How do attitudes shape childbearing in the United States? In: The new population problem (why families in developed countries are sinking and what it means), eds A. Booth and A. Crouter, Mahwah, New Jersey, London: Lawrence Erlbaum Associates Publishers.

Beck, U. and E. Beck-Gernsheim 1995. The Normal Chaos of Love. London: Polity Press.

Berrington, A., B. Perelli-Harris and P. Trevena 2015. Commitment and the changing sequence of cohabitation, childbearing, and marriage: insights from qualitative research in the UK. Demographic Research 33(12): 327-362.

Billari, F. C., D. Philipov and M. R. Testa 2009. Attitudes, norms, and perceived behavioural control: explaining fertility intentions in Bulgaria. European Journal of Population 25(4): 439-465.

Billari, F. C. and D. Philipov 2004. Education and transition to motherhood: a comparative analysis of Western Europe. European Demographic Research Papers, No. 3, Vienna: Vienna Institute of Demography, Austrian Academy of Sciences. 
Blossfeld, H. P., E. Klijzing, M. Mills and M. Kurz (eds) 2005. Globalization, uncertainty and youth in society. London: Routledge.

Blossfeld, H.-P. and J. Huinink 1991. Human capital investments or norms of role transition? How women's schooling and career affect the process of family formation. American Journal of Sociology 97: 143-168.

Buber-Ennser, I., N. Neuwirth and M. R. Testa (eds) 2014. Families in Austria: 2009-2013. Descriptive findings on partnerships, fertility intentions, childbearing and child-rearing. GGS Report. Vienna Institute of Demography of the Austrian Academy of Science.

Dommermuth, L., J. Klobas and T. Lappergård 2011. Now or later? The theory of planned behaviour and timing of fertility intentions. Advances in Life Course Research 16: 42-53.

Dykstra, P. A. and L. van Wissen, (1999). Introduction: the life course approach as an interdisciplinary framework for population studies. In Population issues: an interdisciplinary focus, eds L. van Wissen and P. A. Dykstra, 1-22. New York: Kluwer Academic.

Elder, G. H. 1985. Perspectives on the life course. In: Life course dynamics: trajectories and transitions, 1968-1980, ed. G. H. Elder, 23-49. Ithaca and London: Cornell University Press.

Elder, G. H., M. Johnson and R. Crosnoe, 2003. The emergence and development of life course theory. In: Handbook of the life course, eds J. Mortimer and M. Shanahan, 3-19. New York: Kluwer Academic.

Fokkema, T., A. Kveder, N. Hiekel, T. Emery and A. Liefbroer 2016. Generations and Gender Programme wave 1 data collection: an overview and assessment of sampling and fieldwork methods, weighting procedure, and cross-sectional representativeness. Demographic Research 34(18): 499-524.

Gauthier, A. H., T. Emery and A. Bartova 2016. The labour market intentions and behaviour of stay-at home mothers in Western and Eastern Europe. Advances in Life Course Research.

Gauthier, A. 2007. The impact of family policies on fertility in industrialized countries: a review of the literature. Population Research and Policy Review 26(3): 323-346.

Giddens, A. 1984. The constitution of society. Outline of the theory of structuration. University of California Press.

Harknett, K. and C. S. Hartnett 2014. The gap between births intended and births achieved in 22 European countries, 2004-07. Population Studies 68(3): 265-282.

Heinz, W. R. 1996. Status passages as micro-macro linkages in life course research. In Society and Biography: Interrelationships between Social Structure, Institutions and the Life Course, eds A. Weymann and W. Heinz, 51-65.

Hiekel, N. and T. Castro-Martin 2014. Grasping the diversity of cohabitation: fertility intentions among cohabiters across Europe. Journal of Marriage and Family 76: 489-505.

Huinink, J. and M. Kohli 2014. A life-course approach to fertility. Demographic Research 30(45): 1293-1326.

Kapitány, B. and Z. Spéder 2013. Realization, postponement or abandonment of childbearing intentions in four European countries. Population 67(4): 599-629.

Mayer, K. U. 2004. Whose lives? How history, societies, and institutions define and shape life courses. Research in Human Development 1: 161-187. 
Mencarini, L., D. Vignoli and A. Gottard 2014. Fertility intentions and outcomes: implementing the theory of planned behaviour with graphical models. Advances in Life Course Research 23: 14-28.

Morgan, S. P. and C. A. Bachrach 2011. Is the theory of planned behaviour an appropriate model for human fertility? Vienna Yearbook of Population Research, Special issue on "Reproductive decision-making", 9: 11-18.

Pailhé, A. 2009. Work-family balance and childbearing intentions in France, Germany and the Russian Federation. In: How Generations and gender shape demographic change. Towards policies based on better knowledge. Conference Proceedings. 14-16 May 2008, Geneva: United Nations Economic Commission for Europe (UNECE): 57-82.

Philipov, D. 2009. The effect of competing intentions and behaviour on short-term childbearing intentions and subsequent childbearing. European Journal of Population 25(4): 525-548.

Schoen, R., N. M. Astone, Y. J. Kim, and C. A. Nathanson 1999. Do fertility intentions affect fertility behaviour? Journal of Marriage and the Family 61(3): 790-799.

Shanahan, M. J. and R. Macmillan 2008. Biography and the sociological imagination. Contexts and contingencies. New York: Norton.

Spéder, Z. and B. Kapitány 2014. Failure to realize fertility intentions: a key aspect of the postcommunist fertility transition. Population Research and Policy Review 33(3): 393-418.

Steele, F. and J. Ermisch 2016. Fertility expectations and residential mobility in Britain. Demographic Research 54: 1561-1584.

Testa, M. R. and L. Toulemon 2006. Family formation in France: individual preferences and subsequent outcomes. Vienna Yearbook of Population Research 5: 41-75.

Thomson, E. and Y. Brandreth 1995. Measuring fertility demand. Demography 32(1): 81-96.

Vidal, S., J. Huinink and M. Feldhaus (2017). Fertility intentions and residential relocations. Demography 54: 1305-1330.

Vikat, A., Z. Spéder, G. Beets, F. C. Billari, C. Bühler, A. Désesquelles, A. Solaz 2007. Generations and Gender Survey (GGS): Towards a better understanding of relationships and processes in the life course. Demographic Research 17(14): 389-440.

Appendix tables are on the following pages. 


\section{Appendix}

Table A.1:

Panel a) Logistic regression on having a child for singles with and without the intention to have a child. Beta coefficients

\begin{tabular}{|c|c|c|c|}
\hline Variables & & $\begin{array}{l}\text { Intended to } \\
\text { have a child }\end{array}$ & $\begin{array}{l}\text { Did not intend } \\
\text { to have a child }\end{array}$ \\
\hline \multicolumn{4}{|l|}{ Intentions variables } \\
\hline Partnership & Enter a partnership, yes & $\begin{array}{c}0.332 \\
(0.266)\end{array}$ & $\begin{array}{c}0.391 \\
(0.318)\end{array}$ \\
\hline Education & Return to education, yes & $\begin{array}{l}-0.712 \\
(0.774)\end{array}$ & $\begin{array}{c}-0.0126 \\
-1,168\end{array}$ \\
\hline Work & Change jobs, yes & $\begin{array}{c}-0.0784 \\
(0.320)\end{array}$ & $\begin{array}{l}-0.108 \\
(0.317)\end{array}$ \\
\hline Residence & Move house, yes & $\begin{array}{c}0.110 \\
(0.266)\end{array}$ & $\begin{array}{l}0.482^{*} \\
(0.254)\end{array}$ \\
\hline \multirow[t]{2}{*}{ Age } & Age & $\begin{array}{c}-0.0739^{* * *} \\
(0.0242)\end{array}$ & $\begin{array}{c}-0.0475^{* *} \\
(0.0242)\end{array}$ \\
\hline & Age squared & $\begin{array}{c}-0.00916^{* * *} \\
(0.00271)\end{array}$ & $\begin{array}{c}-0.00594^{*} \\
(0.00323)\end{array}$ \\
\hline Gender (ref. Male) & Female & $\begin{array}{c}0.234 \\
(0.262)\end{array}$ & $\begin{array}{c}-0.0173 \\
(0.257)\end{array}$ \\
\hline $\begin{array}{l}\text { Parity } \\
\text { (ref. No child) }\end{array}$ & At least one child & $\begin{array}{l}0.608^{*} \\
(0.368)\end{array}$ & $\begin{array}{l}0.834^{* *} \\
(0.391)\end{array}$ \\
\hline \multirow[t]{2}{*}{$\begin{array}{l}\text { Education } \\
\text { (ref. Medium) }\end{array}$} & Low level & $\begin{array}{l}-0.138 \\
(0.699)\end{array}$ & $\begin{array}{c}0.311 \\
(0.662)\end{array}$ \\
\hline & High level & $\begin{array}{c}-0.613^{*} \\
(0.327)\end{array}$ & $\begin{array}{l}-0.580 \\
(0.382)\end{array}$ \\
\hline \multirow[t]{2}{*}{$\begin{array}{l}\text { Employment } \\
\text { (ref. Employed) }\end{array}$} & Unemployed & $\begin{array}{l}-0.115 \\
(0.370)\end{array}$ & $\begin{array}{c}0.171 \\
(0.396)\end{array}$ \\
\hline & Housework & $\begin{array}{l}-0.107 \\
(0.747)\end{array}$ & $\begin{array}{l}1,107 \\
(0.969)\end{array}$ \\
\hline \multirow[t]{2}{*}{$\begin{array}{l}\text { Country } \\
\text { (ref. Bulgaria) }\end{array}$} & France & $\begin{array}{l}-0.618 \\
(0.722)\end{array}$ & $\begin{array}{l}-0.528 \\
(0.676)\end{array}$ \\
\hline & Austria & $\begin{array}{l}0.0391 \\
(0.284)\end{array}$ & $\begin{array}{l}1.286^{* * *} \\
(0.316)\end{array}$ \\
\hline Constant & & $\begin{array}{c}-4.448^{* * *} \\
(0.971)\end{array}$ & $\begin{array}{c}-2.570^{*} \\
(1.383)\end{array}$ \\
\hline Sample size & & 2,294 & 835 \\
\hline
\end{tabular}

Note: Standard errors in parentheses. ${ }^{* * *} p<0.01,{ }^{* *} p<0.05,{ }^{*} p<0.1$. 
Table A.1:

Panel b) Logistic regression on having a child for couples with and without the intention to have a child. Beta coefficients

\begin{tabular}{|c|c|c|c|}
\hline Variables & Labels & $\begin{array}{l}\text { Intended to } \\
\text { have a child }\end{array}$ & $\begin{array}{l}\text { Did not intend } \\
\text { to have a child }\end{array}$ \\
\hline \multicolumn{4}{|l|}{ Intentions variables } \\
\hline Partnership & Get married, yes & $\begin{array}{l}0.0964 \\
(0.148)\end{array}$ & $\begin{array}{c}0.103 \\
(0.209)\end{array}$ \\
\hline Education & Return to education, yes & $\begin{array}{c}1,027 \\
-1,294\end{array}$ & $\begin{array}{c}-0.0183 \\
-1,231\end{array}$ \\
\hline Work & Change jobs, yes & $\begin{array}{c}-0.217^{*} \\
(0.112)\end{array}$ & $\begin{array}{l}0.330^{* *} \\
(0.162)\end{array}$ \\
\hline Residence & Move house, yes & $\begin{array}{l}0.184^{* *} \\
(0.0905)\end{array}$ & $\begin{array}{l}0.260^{* *} \\
(0.126)\end{array}$ \\
\hline \multicolumn{4}{|l|}{ Control variables } \\
\hline \multirow[t]{2}{*}{ Age } & Age & $\begin{array}{c}-0.137^{* * * *} \\
(0.0280)\end{array}$ & $\begin{array}{c}-0.303^{* * *} \\
(0.0380)\end{array}$ \\
\hline & Age squared & $\begin{array}{c}-0.00272^{* *} \\
(0.00107)\end{array}$ & $\begin{array}{c}-0.00552^{* * *} \\
(0.00148)\end{array}$ \\
\hline $\begin{array}{l}\text { Gender } \\
\text { (ref. Male) }\end{array}$ & Female & $\begin{array}{l}-0.0373 \\
(0.0983)\end{array}$ & $\begin{array}{c}-0.669^{* * *} \\
(0.145)\end{array}$ \\
\hline $\begin{array}{l}\text { Parity } \\
\text { (ref. No child) }\end{array}$ & At least one child & $\begin{array}{c}-0.396^{* * *} \\
(0.105)\end{array}$ & $\begin{array}{l}-0.136 \\
(0.200)\end{array}$ \\
\hline \multirow[t]{2}{*}{$\begin{array}{l}\text { Education } \\
\text { (ref. Medium level) }\end{array}$} & Low level & $\begin{array}{c}0.115 \\
(0.387)\end{array}$ & $\begin{array}{c}0.393 \\
(0.313)\end{array}$ \\
\hline & High level & $\begin{array}{c}0.141 \\
(0.178)\end{array}$ & $\begin{array}{c}-0.380^{* *} \\
(0.156)\end{array}$ \\
\hline \multirow[t]{2}{*}{$\begin{array}{l}\text { P Education } \\
\text { (ref. Medium level) }\end{array}$} & Low level & $\begin{array}{c}0.263 \\
(0.225)\end{array}$ & $\begin{array}{l}0.508^{* *} \\
(0.254)\end{array}$ \\
\hline & High level & $\begin{array}{c}0.176^{*} \\
(0.0908)\end{array}$ & $\begin{array}{l}0.231^{*} \\
(0.128)\end{array}$ \\
\hline \multirow[t]{3}{*}{$\begin{array}{l}\text { Employment } \\
\text { (ref. Employed) }\end{array}$} & Unemployed & $\begin{array}{l}0.459^{* *} \\
(0.180)\end{array}$ & $\begin{array}{l}0.0687 \\
(0.219)\end{array}$ \\
\hline & Housework & $\begin{array}{c}0.437^{* * *} \\
(0.169)\end{array}$ & $\begin{array}{l}0.377^{*} \\
(0.210)\end{array}$ \\
\hline & Enrolled & $\begin{array}{l}-0.263 \\
(0.625)\end{array}$ & $\begin{array}{l}-0.138 \\
(0.691)\end{array}$ \\
\hline \multirow[t]{3}{*}{$\begin{array}{l}\text { P. employment } \\
\text { (ref. Employed) }\end{array}$} & Unemployed & $\begin{array}{c}-0.908^{* *} \\
(0.386)\end{array}$ & $\begin{array}{c}0.140 \\
(0.337)\end{array}$ \\
\hline & Housework & $\begin{array}{l}-0.140 \\
(0.179)\end{array}$ & $\begin{array}{c}-0.0308 \\
(0.197)\end{array}$ \\
\hline & Enrolled & $\begin{array}{c}0.490^{* * *} \\
(0.153)\end{array}$ & $\begin{array}{l}0.354^{* * *} \\
(0.179)\end{array}$ \\
\hline
\end{tabular}

Continued 
Table A.1:

Panel b) Continued

\begin{tabular}{lccc}
\hline Variables & Labels & $\begin{array}{c}\text { Intended to } \\
\text { have a child }\end{array}$ & $\begin{array}{c}\text { Did not intend } \\
\text { to have a child }\end{array}$ \\
\hline Country & France & $1.238^{* * *}$ & -0.462 \\
(ref. Bulgaria) & & $(0.381)$ & $(0.353)$ \\
& Hungary & $0.755^{* * *}$ & $1.137^{* * *}$ \\
& & $(0.132)$ & $(0.167)$ \\
& Austria & $1.355^{* * *}$ & $0.835^{* * *}$ \\
& & $(0.139)$ & $(0.198)$ \\
& Lithuania & 0.215 & 0.205 \\
& & $(0.213)$ & $(0.328)$ \\
Constant & & $-3.748^{* * *}$ & $-5.585^{* * *}$ \\
& & $(1.416)$ & $(1.323)$ \\
Sample size & & 2,727 & 8,583 \\
\hline
\end{tabular}

Note: Standard errors in parentheses. ${ }^{* * *} p<0.01,{ }^{* *} p<0.05,{ }^{*} p<0.1$. 